\title{
The Relationship between the Presence of White Nails and Mortality among Rural, Older, Admitted Patients: A Prospective Cohort Study
}

\author{
Ryuichi Ohta ${ }^{1, *(\mathbb{D})}$, Yoshinori Ryu ${ }^{1}$ and Chiaki Sano ${ }^{2}$ (I) \\ 1 Community Care, Unnan City Hospital, 699-1221 96-1 Iida, Daito-cho, \\ Unnan 699-1221, Shimane Prefecture, Japan; yoshiyoshiryuryu.hpydys@gmail.com \\ 2 Department of Community Medicine Management, Faculty of Medicine, Shimane University, 89-1 Enya cho, \\ Izumo 693-8501, Shimane Prefecture, Japan; sanochi@med.shimane-u.ac.jp \\ * Correspondence: ryuichiohta0120@gmail.com; Tel.: +81-90-506-0533
}

check for

updates

Citation: Ohta, R.; Ryu, Y.; Sano, C. The Relationship between the Presence of White Nails and Mortality among Rural, Older, Admitted

Patients: A Prospective Cohort Study. Healthcare 2021, 9, 1611. https:// doi.org/10.3390/healthcare9121611

Received: 18 October 2021

Accepted: 22 November 2021

Published: 23 November 2021

Publisher's Note: MDPI stays neutral with regard to jurisdictional claims in published maps and institutional affiliations.

Copyright: (c) 2021 by the authors. Licensee MDPI, Basel, Switzerland. This article is an open access article distributed under the terms and conditions of the Creative Commons Attribution (CC BY) license (https:// creativecommons.org/licenses/by/ $4.0 /)$.

\begin{abstract}
White nails are a sign of various physical deteriorations, including poor nutrition, organ damage, and aging. During a physical examination, white nails can be a helpful health indicator in older patients with vague and multiple symptoms. In this prospective cohort study of patients admitted to the Department of General Medicine in a rural community hospital, we investigated the relationship between white nails and patient mortality. Patient data, including age, sex, condition, and bloodwork results, were collected. Trained family physicians confirmed the presence of white nails. Logistic regression analysis was performed to determine the relationship between white nails and death during hospitalization. Of 711 study participants, 74 died during hospitalization. White nails, male sex, and caregiver dependence were associated with high in-hospital mortality (odds ratio $(\mathrm{OR})=3.47, p<0.001$; OR 2.05, $p=0.01$; OR 1.92, $p=0.049$, respectively). High albumin concentration was associated with low in-hospital mortality $(\mathrm{OR}=0.44, p<0.001)$. White nails, along with serum albumin concentration, male sex, and caregiver dependence, are associated with mortality. The identification of white nails can predict the deterioration of patients. Various professionals should learn to identify the presence of white nails to facilitate the care of elderly patients.
\end{abstract}

Keywords: white nail; mortality; general medicine; older patient; rural; community hospital

\section{Introduction}

Changes in nail conditions can indicate various systematic changes in the human body, such as poor nutrition and chronic disease [1]. Nail color changes, which occur gradually, can occur in nail plates or nail beds $[2,3]$. These changes can indicate chronic changes in the human body [4-6]. Patients with heart failure, liver cirrhosis, and advanced age experience whitening of the nails, with the distal parts of the nails turning brown due to telangiectasis; this condition is called Terry's nail $[7,8]$. A poor nutritional status can progressively cause Terry's nail [9]. On the other hand, whitening of the nails with brown distal nail parts due to melanin deposition is called Lindsay's nail; this is indicative of malnutrition and renal disease [10]. The mechanism underlying Terry's and Lindsay's nails is not fully understood. Given that nail plates and nail bed conditions may not change quickly in response to acute diseases, these changes can be called static physical findings [11]. The state of patients' nails may be indicative of their nutritional and chronic disease status. Given that nutritional conditions can affect the clinical progression of patients with acute diseases, nail health can be used as a predictive risk factor for patients' morbidity and mortality.

The examination of nails has been considered helpful for clinical reasoning in clinical settings. However, in examinations of older patients, differentiation of the findings of nail examination can be difficult. One of the reasons for this is multimorbidity. Older patients often have multiple chronic diseases that affect their health conditions, which modify their 
physical presentation and examination findings [12]. Specific nail examination findings can indicate several possible medical conditions and cannot reveal the presence of a particular disease [2]. Aging can change nail plate and nail bed conditions due to atherosclerosis and fibrosis of the peripheral tissues [13]. In these circumstances, including Lindsay's or Terry's nails, nail color typically changes to white. Both conditions reportedly indicate the presence of liver and renal diseases [7,10]. However, differentiating between Lindsay's and Terry's nails is difficult because these names are used interchangeably in previous research $[7,10]$. Furthermore, although aging can affect nail conditions, the prevalence of these changes in the older generation is not well understood [10]. In countries with older populations, nail examination should be considered and investigated for use in clinical situations. Abnormal nail findings should be defined (i.e., a white nail without a lunula) [11]. Currently, there is no information on the distribution of nail changes or whether the changes are transient. Nail changes are more common in the nails of all fingers except the nail of the first finger. Changes can be present mainly in the nail beds of fingers associated with various chronic diseases [11]. Thus, during the physical examination of patients with systemic conditions, physicians can note nail changes on all digits.

The presence of white nails can provide critical information in older patients and may be related to their prognoses. White nails can be the result of various biomedical conditions, such as renal and liver disease or a poor nutritional condition, which can be related to morbidity and mortality in patients [11]. Therefore, white nails can be related to patients' clinical outcomes. However, no studies have investigated the specific relationship between the presence of white nails and patient health outcomes. Nail conditions can change with aging, and the prevalence of white nails can change among the elderly [14]. Acute changes in body fluids, dynamic physical findings, and laboratory data can make the prediction of general conditions difficult. The presence of white nails may indicate the condition and vulnerability of older patients at admission and is not affected by acute changes in medical conditions. However, there are no studies regarding the relationship between white nails and readmission and mortality rates. Therefore, we sought to determine the relationship between the presence of white nails and in-hospital mortality among older patients. As societies age, comprehensive assessments of older patients' conditions, including an examination of nail conditions, can be vital for rural and home care due to the lack of healthcare resources. The purpose of this study was to investigate the relationship between white nails and mortality rates among older patients in rural community hospitals.

\section{Materials and Methods}

This study was a prospective cohort study of patients admitted to the Department of General Medicine in a rural community hospital.

\subsection{Setting}

Unnan City is one of the most rural cities in Japan and is located in the southeast of Shimane Prefecture. In 2020, the total population of Unnan was 37,638 (18,145 males and 19,492 females), with $39 \%$ aged over 65 years, which is expected to reach $50 \%$ by 2025 . There are 16 clinics, 12 home care stations, three visiting nurse stations, and only one public hospital (Unnan City Hospital) [15]. At the time of this study, Unnan City Hospital had 281 beds comprising 160 acute care beds, 43 comprehensive care beds, 30 rehabilitation beds, and 48 chronic care beds. There were 14 medical specialties, and the nurse-to-patient ratio was 1:10 for acute care, 1:13 for comprehensive care, 1:15 for rehabilitation, and 1:25 for chronic care. Patient care was managed by family physicians and nurses in the acute care division. Patients were regularly followed up at Unnan City Hospital or other medical institutions in Unnan City from 1 April 2020 to 30 June 2021. All readmissions were performed at the Unnan City Hospital [16]. 


\subsection{Participants}

All patients over 65 years of age who were admitted to Unnan City Hospital and discharged from or died at the hospital from 1 April 2020 to 31 March 2021 were included in this study. The study period was from 1 April 2020 to 30 June 2021 to observe the mortality rate. Patients who lost their fingers, had fungal infections of the nails, had traumatic nail deformations, had white spots warranting referral to the dermatologist, underwent potassium hydroxide testing, and those referred to other specialties were excluded from the present study.

\subsection{Measurements}

\subsubsection{Assessment of White Nails}

White nails were characterized by a white appearance of the proximal nails without a lunula [11]. Changes in the distal part of the nail caused by deposition of melanin were not considered in the assessment of white nails $[7,10]$. The nail lunula can be diminished in all fingers, but the lunula of the first finger is often persistent, even in older individuals. All assessors evaluated patients' nails for the appearance of whitening of the nails upon admission and were unaware of the endpoints of the patients. To improve the precision of the diagnosis of white nails, the family physicians who performed the nail examinations in this study were trained and tested using clinical pictures of white nails from a previous study [11]. During training, family physicians identified and discussed white nails while examining patients using the previous study as a reference [11]. This training period lasted approximately three months before patients were enrolled into the study [11]. During the first month of training, the family physicians read previous articles to learn about while nails and observed their patients. In regular clinical rounds, attending family physicians presented the conditions of the patients' nails and discussed the presence of apparent whitening, using the definitions in this study as references. This process continued for the following two months to improve their ability to detect the presence of white nails. To improve the reliability of the diagnoses, participants were evaluated by more than two family physicians. If there were discrepancies between the assessors, additional assessors examined the participants and discussed the appearance of their nails until an agreement was reached.

\subsubsection{The Patients' Data}

The participants' background information was extracted from the electronic health records of Unnan City Hospital. Data were collected concerning the participants' age, sex, body mass index (BMI), albumin concentration, serum creatinine levels, estimated glomerular filtration rate (eGFR), and care level based on the Japanese long-term insurance system [17]. In addition, Charlson comorbidity indices (CCIs) based on past medical histories (the presence of heart failure, myocardial infarction, asthma, chronic obstructive pulmonary diseases, kidney diseases, liver diseases, diabetes mellitus, brain infarction, brain hemorrhage, hemiplegia, connective tissue diseases, dementia, and cancer) [18], admission duration, and death during admission were assessed.

\subsubsection{Analysis}

The student's t-test was performed on parametric data, and the Mann-Whitney U test was performed on non-parametric data. Based on previous studies and the average of variables, numerical variables were dichotomized as follows: CCI $(\geq 5$ and $<5)$ [18] and care level ( $\geq 1$ and 0 ) based on the burden on caregivers and families [17]. A univariate regression model was used to assess whether mortality was associated with the independent variables, including the presence of white nails. Variables with statistically significant differences in the univariate regression analysis were further analyzed using a logistic regression model. Regarding the sample size calculation, 219 participants would be needed with $80 \%$ statistical power and $5 \%$ type 1 error to detect a difference in the percentage of death of $10 \%$ between the white nail and non-white nail groups. Cases with missing data 
were excluded from the analysis. Statistical significance was defined as a $p$-value $<0.05$. All statistical analyses were performed using EZR (Saitama Medical Center, Jichi Medical University, Saitama, Japan), which is a graphical user interface for R (The R Foundation, Vienna, Austria).

\subsubsection{Ethical Considerations}

The hospital was assured of the anonymity and confidentiality of the patients' information. Information about the study was posted on the hospital website without disclosure of the patients' details. To address any questions regarding this study, the contact information of the hospital representative was also posted on the website. All participants were informed about the purpose of this study, and written informed consent was obtained from all participants or their families. The Clinical Ethics Committee of our institution approved this study (Approved date: 1 March 2020).

\section{Results}

\subsection{The Demographic of the Participants}

Of the 2894 patients admitted to the community hospital, 748 were admitted to the Department of General Medicine. After excluding 37 patients with missing data, 711 participants were evaluated. The patient inclusion flowchart is presented in Figure 1. Of the participants, $29.8 \%$ had white nails. The average participant age was 81.95 (standard deviation $(\mathrm{SD})=13.63$ ). Of the patients evaluated, $44.4 \%$ were male. Statistically significant differences in age, sex, albumin concentration, BMI, the presence of white nails, CCI, caregiver dependence, and admission duration were present when comparing patients who died during the study period with those who did not (Table 1).

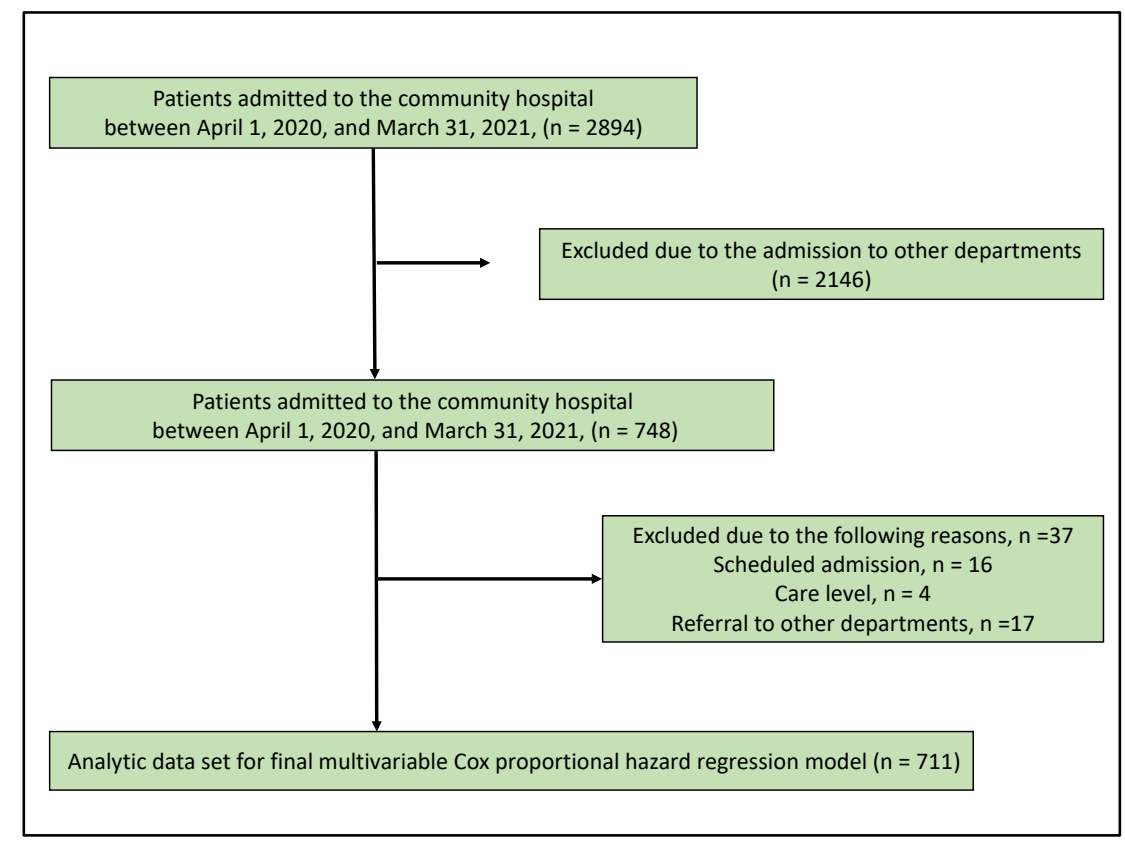

Figure 1. The flow chart of patient selection.

\subsection{The Relationship between the Presence of White Nails and Mortality}

A multivariate logistic regression model was used to determine the association between the independent variables and in-hospital mortality. The independent variables included age, sex, albumin concentration, BMI, presence of white nails, CCI, caregiver dependence, and admission duration. The presence of white nails, (odds ratio $(\mathrm{OR})=3.47$, $p<0.001)$, male sex $(\mathrm{OR}=2.05, p=0.01)$, and caregiver dependance $(\mathrm{OR}=1.92, p=0.049)$ were associated with high in-hospital mortality. Conversely, a high albumin concentration was associated with low in-hospital mortality $(\mathrm{OR}=0.44, p<0.001)$. There was no statisti- 
cally significant relationship between the other variables assessed and in-hospital mortality (Table 2).

Table 1. Patient demographics.

\begin{tabular}{|c|c|c|c|c|}
\hline \multirow[b]{2}{*}{ Factor } & \multirow[b]{2}{*}{ Total } & \multicolumn{2}{|c|}{ Death } & \multirow[b]{2}{*}{$p$-Value } \\
\hline & & Yes & No & \\
\hline $\mathrm{n}$ & 711 & 74 & 637 & \\
\hline Age (years), mean (SD) & $81.95(13.63)$ & $88.41(6.59)$ & $81.20(14.03)$ & $<0.001$ \\
\hline male sex $(\%)$ & $316(44.4)$ & $41(55.4)$ & $275(43.2)$ & 0.049 \\
\hline albumin, mean (SD) & $3.49(0.66)$ & $2.96(0.54)$ & $3.55(0.64)$ & $<0.001$ \\
\hline height, mean (SD) & $153.37(10.44)$ & $152.73(9.91)$ & $153.45(10.51)$ & 0.577 \\
\hline body weight, mean (SD) & $48.69(11.69)$ & $44.51(8.67)$ & $49.18(11.90)$ & 0.001 \\
\hline BMI, mean (SD) & $20.59(3.93)$ & $19.10(3.34)$ & $20.76(3.96)$ & 0.001 \\
\hline creatinine & $1.05(1.09)$ & $1.07(0.78)$ & $1.04(1.12)$ & 0.865 \\
\hline eGFR & $58.75(22.41)$ & $57.85(25.78)$ & $58.86(22.01)$ & 0.714 \\
\hline white nail $(\%)$ & $212(29.8)$ & $54(73.0)$ & $158(24.8)$ & $<0.001$ \\
\hline Admission duration (IQR]) & $15.00(1.00,167.00)$ & $24.50(1.00,146.00)$ & $15.00(1.00,167.00)$ & $<0.001$ \\
\hline $\mathrm{CCI} \geq 5(\%)$ & $423(59.5)$ & $55(74.3)$ & $368(57.8)$ & 0.006 \\
\hline \multicolumn{5}{|l|}{$\mathrm{CCI}(\%)$} \\
\hline 0 & $26(3.7)$ & $0(0.0)$ & $26(4.1)$ & \\
\hline 1 & $17(2.4)$ & $0(0.0)$ & $17(2.7)$ & \\
\hline 2 & $28(3.9)$ & $0(0.0)$ & $28(4.4)$ & \\
\hline 3 & $50(7.0)$ & $2(2.7)$ & $48(7.5)$ & \\
\hline 4 & $167(23.5)$ & $17(23.0)$ & $150(23.5)$ & \\
\hline 5 & $147(20.7)$ & $15(20.3)$ & $132(20.7)$ & \\
\hline 6 & $112(15.8)$ & $15(20.3)$ & $97(15.2)$ & \\
\hline 7 & $92(12.9)$ & $12(16.2)$ & $80(12.6)$ & \\
\hline 8 & $34(4.8)$ & $4(5.4)$ & $30(4.7)$ & \\
\hline 9 & $21(3.0)$ & $2(2.7)$ & $19(3.0)$ & \\
\hline 10 & $7(1.0)$ & $3(4.1)$ & $4(0.6)$ & \\
\hline 11 & $5(0.7)$ & $3(4.1)$ & $2(0.3)$ & \\
\hline 12 & $2(0.3)$ & $0(0.0)$ & $2(0.3)$ & \\
\hline 13 & $1(0.1)$ & $0(0.0)$ & $1(0.2)$ & \\
\hline 14 & $1(0.1)$ & $1(1.4)$ & $0(0.0)$ & \\
\hline 15 & $1(0.1)$ & $0(0.0)$ & $1(0.2)$ & \\
\hline heart failure (\%) & $126(17.7)$ & $17(23.0)$ & $109(17.1)$ & 0.202 \\
\hline MI $(\%)$ & $56(7.9)$ & $9(12.2)$ & $47(7.4)$ & 0.168 \\
\hline asthma (\%) & $36(5.1)$ & $4(5.4)$ & $32(5.0)$ & 0.782 \\
\hline peptic ulcer $(\%)$ & $60(8.5)$ & $2(2.7)$ & $58(9.1)$ & 0.074 \\
\hline kidney disease (\%) & $55(7.7)$ & $5(6.8)$ & $50(7.8)$ & 1 \\
\hline liver disease $(\%)$ & $26(3.7)$ & $2(2.7)$ & $24(3.8)$ & 1 \\
\hline COPD $(\%)$ & $41(5.8)$ & $8(10.8)$ & $33(5.2)$ & 0.062 \\
\hline $\mathrm{DM}(\%)$ & $106(14.9)$ & $9(12.2)$ & $97(15.2)$ & 0.605 \\
\hline brain infarction $(\%)$ & $128(18.0)$ & $11(14.9)$ & $117(18.4)$ & 0.525 \\
\hline brain hemorrhage $(\%)$ & $53(7.5)$ & $7(9.5)$ & $46(7.2)$ & 0.482 \\
\hline hemiplegia $(\%)$ & $23(3.2)$ & $2(2.7)$ & $21(3.3)$ & 1 \\
\hline connective tissue disease (\%) & $26(3.7)$ & $2(2.7)$ & $24(3.8)$ & 1 \\
\hline dementia $(\%)$ & $131(18.4)$ & $16(21.6)$ & $115(18.1)$ & 0.432 \\
\hline cancer $(\%)$ & $141(19.8)$ & $27(36.6)$ & $114(17.9)$ & 0.001 \\
\hline caregiver dependence $(\%)$ & $313(44.0)$ & $55(74.3)$ & $258(40.5)$ & $<0.001$ \\
\hline \multicolumn{5}{|l|}{ care level $(\%)$} \\
\hline 0 & $398(56.0)$ & $19(25.7)$ & $379(59.5)$ & \\
\hline 1 & $51(7.2)$ & $4(5.4)$ & $47(7.4)$ & \\
\hline 2 & $83(11.7)$ & $16(21.6)$ & $67(10.5)$ & \\
\hline 3 & $78(11.0)$ & $15(20.3)$ & $63(9.9)$ & \\
\hline 4 & $57(8.0)$ & $11(14.9)$ & $46(7.2)$ & \\
\hline 5 & $44(6.2)$ & $9(12.2)$ & $35(5.5)$ & \\
\hline
\end{tabular}

Abbreviations: BMI, body mass index; eGFR, estimated glomerular filtration rate; CCI, Charlson comorbidity indices; MI, myocardial infarction; COPD, chronic obstructive pulmonary diseases; DM, diabetes mellitus; IQR, interquartile range; SD, standard deviation. 
Table 2. Multivariate logistic regression model for the relationship between in-hospital mortality and independent variables.

\begin{tabular}{cccc}
\hline Factor & Odds Ratio & $\mathbf{9 5 \%}$ CI & $p$-Value \\
\hline Age & 1.03 & $1.00-1.07$ & 0.069 \\
Male sex & 2.05 & $1.18-3.53$ & 0.01 \\
Albumin concentration & 0.44 & $0.27-0.72$ & $<0.001$ \\
BMI & 0.97 & $0.90-1.04$ & 0.39 \\
CCI $\geq 5$ & 0.92 & $0.49-1.72$ & 0.79 \\
Caregiver dependence & 1.92 & $1.00-3.67$ & 0.049 \\
White nail & 3.47 & $1.85-6.49$ & $<0.001$ \\
Admission duration & 1.00 & $1.00-1.01$ & 0.5 \\
\hline
\end{tabular}

Abbreviations: BMI, body mass index; CCI, Charlson comorbidity index.

\subsection{Reasons for Hospital Admission}

The most common reason for hospital admission was heart failure (11.8\%), followed by urinary tract infection $(11.5 \%)$, brain stroke $(8.2 \%)$, bacterial pneumonia $(6.0 \%)$, and aspiration pneumonia (5.9\%) (Table 3$)$.

Table 3. The prevalence of the reasons for admission.

\begin{tabular}{|c|c|c|c|c|c|}
\hline Disease & $\mathbf{N}$ & Percentage & Disease & $\mathbf{N}$ & Percentage \\
\hline heart failure & 84 & $11.8 \%$ & Hypothyroidism & 5 & $0.7 \%$ \\
\hline urinary tract infection & 82 & $11.5 \%$ & Hypoglycemia & 5 & $0.7 \%$ \\
\hline brain stroke & 58 & $8.2 \%$ & hepatic encephalopathy & 5 & $0.7 \%$ \\
\hline bacterial pneumonia & 43 & $6.0 \%$ & Clostridium difficile colitis & 5 & $0.7 \%$ \\
\hline aspiration pneumonia & 42 & $5.9 \%$ & vitamin B1 sufficiency & 5 & $0.7 \%$ \\
\hline cancer & 23 & $3.2 \%$ & transient ischemic attack & 4 & $0.6 \%$ \\
\hline brain hemorrhage & 20 & $2.8 \%$ & myocardial infarction & 4 & $0.6 \%$ \\
\hline trauma & 19 & $2.7 \%$ & Dehydration & 4 & $0.6 \%$ \\
\hline syncope & 18 & $2.5 \%$ & gastroesophageal reflux disease & 4 & $0.6 \%$ \\
\hline pseudogout & 17 & $2.4 \%$ & varicella zoster virus infection & 3 & $0.4 \%$ \\
\hline sepsis & 17 & $2.4 \%$ & Type 2 respiratory failure & 3 & $0.4 \%$ \\
\hline gastrointestinal bleeding & 16 & $2.3 \%$ & temporal arteritis & 3 & $0.4 \%$ \\
\hline epilepsy & 15 & $2.1 \%$ & septic vertebritis & 3 & $0.4 \%$ \\
\hline cellulitis & 14 & $2.0 \%$ & Pancreatitis & 3 & $0.4 \%$ \\
\hline chronic obstructive lung disease & 11 & $1.5 \%$ & diabetic ketoacidosis & 3 & $0.4 \%$ \\
\hline ischemic colitis & 11 & $1.5 \%$ & polymyalgia rheumatica & 3 & $0.4 \%$ \\
\hline peripheral vertigo & 11 & $1.5 \%$ & urinary stone & 2 & $0.3 \%$ \\
\hline fever & 9 & $1.3 \%$ & Tuberculosis & 2 & $0.3 \%$ \\
\hline unconsciousness & 9 & $1.3 \%$ & Tsutsugamushi & 2 & $0.3 \%$ \\
\hline loss of appetite & 8 & $1.1 \%$ & normal pressure hydrocephalus & 2 & $0.3 \%$ \\
\hline acute enteritis & 8 & $1.1 \%$ & liver abscess & 2 & $0.3 \%$ \\
\hline cholangitis & 7 & $1.0 \%$ & iron deficiency anemia & 2 & $0.3 \%$ \\
\hline Parkinson's syndrome & 6 & $0.8 \%$ & Headache & 2 & $0.3 \%$ \\
\hline angina & 6 & $0.8 \%$ & Guillain-Barré syndrome & 2 & $0.3 \%$ \\
\hline peptic ulcer & 6 & $0.8 \%$ & Constipation & 2 & $0.3 \%$ \\
\hline medication-induced & 6 & $0.8 \%$ & Anaphylaxis & 2 & $0.3 \%$ \\
\hline electrolyte disturbance & 6 & $0.8 \%$ & Alcoholism & 2 & $0.3 \%$ \\
\hline pneumothorax & 5 & $0.7 \%$ & anterior cutaneous nerve entrapment syndrome & 2 & $0.3 \%$ \\
\hline Ileus & 5 & $0.7 \%$ & hypertensive emergency & 2 & $0.3 \%$ \\
\hline meningitis & 5 & $0.7 \%$ & Others & 36 & $5.1 \%$ \\
\hline
\end{tabular}

Other reasons for admission included tonsillitis, sudden deafness, superior mesenteric artery (SMA) syndrome, spontaneous bacterial peritonitis, sarcoidosis, renal failure, pulmonary embolism, paroxysmal supraventricular tachycardia, polymyositis, pleuritis, parotitis, non-tuberculosis mycobacterium, microscopic polyangiitis, liver cirrhosis, infectious mononucleosis, hyperthermia, human immunodeficiency virus (HIV), hepatitis, hemoptysis, Hashimoto encephalitis, fatigue, functional dyspepsia, erysipelas, eosinophilic 
gastritis, dyspnea, drowning, depression, chronic pleuritis, chronic fatigue syndrome, bronchitis, atrial fibrillation, asthma, amyotrophic lateral sclerosis, adrenal insufficiency, and acute disseminated encephalomyelitis.

\section{Discussion}

This prospective cohort study demonstrated that the presence of white nails was associated with mortality during hospital admission among older rural patients. The effect remained after adjusting for other independent variables related to mortality in hospitals. Among older people, serum albumin concentration, male sex, and caregiver dependence were found to be related to in-hospital mortality. The reasons for admission were common diseases among older patients. This study indicates that the consideration of nail condition during the physical examination of older people is an informative diagnostic assessment tool.

The importance of examining nails for whitening should be emphasized when examining older hospitalized patients to predict their risk of mortality. This study shows the relationship between white nails and mortality rates among older admitted patients. In general, older patients present with various symptoms and physical findings related to their medical histories and nutritional status $[19,20]$. Therefore, clinicians should consider the conditions of older patients comprehensively, including information on symptoms, physical findings, and other clinical data in their assessment $[19,21]$. Compared to other physical findings of major organs, such as the lungs and heart, nails and hands can be quickly examined in outpatient clinics and during bedside examinations without the need for sophisticated equipment or diagnostic tools. In addition, mortality in older patients can be affected by nutrition, age, and previous medical conditions [22,23]. As this study shows, the presence of white nails is an independent factor related to patient mortality and is most likely interrelated to these factors. Therefore, clinicians must be aware of nail conditions and their relationship to the worsening of more serious conditions. The pathophysiology of white nails can be explained by various factors other than nutrition as changes in the color of the nail plate can be the result of vascular changes or substance deposition $[1,14,24]$. In this study, the presence of liver and renal diseases was not related to the mortality rate in hospitals. The presence of white nails, which can be transient, may not be due to liver and kidney diseases [11]. Future studies should be carried out to elucidate the pathophysiology of white nails in depth. Furthermore, if vascular conditions can cause nail whitening, the color of the nail can change by increasing peripheral perfusion, which often alleviates the symptoms and conditions of diseases. Future studies should investigate the relationship between restorative changes in nail color upon admission and mortality among older patients.

Various clinical factors are related to the mortality of older patients admitted to community hospitals. First, serum albumin levels may be strongly related to the mortality of older admitted patients. Serum albumin is affected by various conditions, such as infections, body volume conditions, and nutritional conditions [25,26]. Low serum albumin concentrations can indicate poor nutritional conditions, which can lead to the inability to make albumin. Severe infections can lead to an increase in immunoglobulin that, in turn, suppresses albumin production, both of which can cause high mortality [27]. Second, males are more likely to die comparatively. Statistically, the longevity of men is lower in developed countries, including Japan [28,29]. Compared to women of the same age, men have higher mortality rates upon admission for acute diseases [29]. Furthermore, men tend to endure their symptoms until they become severe. This hesitancy to seek medical attention or help-seeking behavior (HSB) is related to a poor clinical course and high mortality [30]. Finally, caregiver dependence can be associated with higher mortality rates. Patients with caregiver dependence must receive help from others to receive medical care, so their HSBs are dependent on their caregivers and healthcare professionals [31]. According to previous studies, caregivers and home care professionals have difficulty judging the severity of older 
patients' symptoms [32-35]. These challenges can cause a delay in seeking medical care, increasing the severity of conditions in caregiver dependent patients.

Common reasons for admission reflect present medical conditions in developed countries. In this study, the most common disease was heart failure $(11.8 \%)$, followed by urinary tract infection $(11.5 \%)$, brain stroke $(8.2 \%)$, bacterial pneumonia $(6.0 \%)$, and aspiration pneumonia (5.9\%), which are common among older people [36-38]. Aging societies have changed the prevalence of diseases in communities, and the need for community hospitals is expanding. Organ-specific specialists cannot manage the increase in the number of heart failures and other cardiovascular diseases. General physicians must manage various diseases in community hospitals, especially in rural settings where fewer specialists are available. Previous studies have shown that the implementation of general medical facilities in rural communities can improve comprehensive care with improved quality of life in rural areas, meaning that general physicians can accommodate various diseases to some extent [39-41]. To support older peoples' lives in homes and hospitals, an adequate understanding of each patient's condition is vital. Thus, examination for the presence of white nails can be helpful for general physicians and various healthcare professionals in assessing the overall health of the individual. Studies should be performed to investigate the relationship between the presence of white nails and hospital admission or readmission rates.

One limitation of this study is the study setting. This study was carried out in a single, rural community hospital that primarily cares for older patients. Other hospital locations may have younger patients to whom these research results cannot be applied. However, considering the current aging of societies in rural areas, the results of this study can be used in various contexts in rural settings. In addition, we diligently followed all of the admitted patients, achieving a low rate of missing data, which would contribute to our findings' reliability. Another limitation is the reliability of the diagnosis of white nails. In this study, family physicians who were trained to identify white nails performed all diagnoses. We focused only on the disappearance of the lunula and whitening of the proximal part of the nail. As there are variations in the whitening of nails and other types of nails, future studies can investigate the extent of whitening and other nail conditions by using transfer learning methods, and the mortality and morbidity of patients in these contexts [42]. Furthermore, the results of the study may be limited by the lack of blinding to the medical histories and the possibility of potential confounding factors affecting the assessment of the white nails. Future studies can evaluate the impact of knowing the patient's history on white nail diagnosis. Potential confounding factors, such as the patient's lifestyle history and the environmental conditions that impact nails, also need to be studied.

\section{Conclusions}

This study indicates that white nails are associated with mortality among older patients admitted in rural settings. Among this group, serum albumin concentration, male sex, and caregiver dependence are also related to mortality. Recognizing the presence of white nails can contribute to the awareness of the severity of individual cases. The identification of white nails can predict the deterioration of elderly patients' conditions. In addition, various professionals can learn to identify the presence of white nails to facilitate the care of older patients.

Author Contributions: R.O. designed, collected, and analyzed the data and prepared and revised the manuscript. Y.R. analyzed the data and revised the manuscript. C.S. analyzed the data and revised the manuscript. All authors have read and agreed to the published version of the manuscript.

Funding: This research received no external funding.

Institutional Review Board Statement: The study was conducted in accordance with the guidelines of the Declaration of Helsinki and was approved by the Clinical Ethics Committee of the Unnan City Hospital (approval number: 20200017, Approved date: 1 March 2020). 
Informed Consent Statement: Written informed consent was obtained from all subjects involved in the study.

Data Availability Statement: The datasets used and/or analyzed during the current study may be obtained from the corresponding author upon reasonable request.

Acknowledgments: We would like to thank all the participants who took part in this research.

Conflicts of Interest: The authors declare no conflict of interest.

\section{References}

1. Fawcett, R.S.; Linford, S.; Stulberg, D.L. Nail Abnormalities: Clues to Systemic Disease. Am. Fam. Phys. 2004, 69, 1417-1424.

2. Sharma, V.; Ramaiya, M. Nail Color and Texture Analysis for Disease Detection. Int. J. Bio-Sci. Bio-Technol. 2015, 7, 351-358. [CrossRef]

3. Ohta, R. Deformed Nail from Stress Related to Childbearing. J. Gen. Fam. Med. 2020, 21, 29. [CrossRef]

4. Baby, T.; Prasad, G.C.; Sunil, S. Nail Changes in Oral Lesions: A Clue to Diagnosis. Trop. J. Med. Res. 2017, 20, 115. [CrossRef]

5. Lipner, S.R.; Scher, R.K. Evaluation of Nail Lines: Color and Shape Hold Clues. Clevel. Clin. J. Med. 2016, 83, 385-391. [CrossRef]

6. Jacobsen, E.; Blenning, C.; Judkins, D. Clinical Inquiry: What Nutritional Deficiencies and Toxic Exposures Are Associated with Nail Changes? J. Fam. Pract. 2012, 61, 164-165.

7. Witkowska, A.B.; Jasterzbski, T.J.; Schwartz, R.A. Terry's Nails: A Sign of Systemic Disease. Indian J. Derm. 2017, 62, 309-311.

8. Khichar, S.; Choudhary, S. Terry Nails in a Patient with Chronic Alcoholic Liver Disease. Clevel. Clin. J. Med. 2014, 81, 603-604. [CrossRef]

9. Yaemsiri, S.; Hou, N.; Slining, M.M.; He, K. Growth Rate of Human Fingernails and Toenails in Healthy American Young Adults. J. Eur. Acad. Derm. Venereol. 2010, 24, 420-423. [CrossRef] [PubMed]

10. Pitukweerakul, S.; Pilla, S. Terry's Nails and Lindsay's Nails: Two Nail Abnormalities in Chronic Systemic Diseases. J. Gen. Intern. Med. 2016, 31, 970. [CrossRef] [PubMed]

11. Ohta, R.; Sano, C. White Nail as a Static Physical Finding: Revitalization of Physical Examination. Clin. Pract. 2021, 11, 36. [CrossRef]

12. Chi, W.C.; Wolff, J.; Greer, R.; Dy, S. Multimorbidity and Decision-Making Preferences among Older Adults. Ann. Fam. Med. 2017, 15, 546-551. [CrossRef] [PubMed]

13. Murdan, S. Nail Disorders in Older People, and Aspects of Their Pharmaceutical Treatment. Int. J. Pharm. 2016, 512, 405-411. [CrossRef] [PubMed]

14. Singh, G.; Haneef, N.S.; Uday, A. Nail Changes and Disorders among the Elderly. Indian J. Derm. Venereol. Leprol. 2005, 71, 386-392. [CrossRef]

15. Ohta, R.; Ryu, Y.; Kataoka, D.; Sano, C. Effectiveness and Challenges in Local Self-Governance: Multifunctional Autonomy in Japan. Int. J. Environ. Res. Public Health 2021, 18, 574. [CrossRef]

16. Ohta, R.; Sano, C. Risk of Hospital Readmission among Older Patients Discharged from the Rehabilitation Unit in a Rural Community Hospital: A Retrospective Cohort Study. J. Clin. Med. 2021, 10, 659. [CrossRef]

17. Shimizutani, S. The Future of Long-Term Care in Japan. Asia Pac. Rev. 2014, 21, 88-119. [CrossRef]

18. Charlson, M.; Szatrowski, T.P.; Peterson, J.; Gold, J. Validation of a Combined Comorbidity Index. J. Clin. Epidemiol. 1994, 47, 1245-1251. [CrossRef]

19. Garg, T.; Polenick, C.A.; Schoenborn, N.; Jih, J.; Hajduk, A.; Wei, M.Y.; Hughes, J. Innovative Strategies to Facilitate PatientCentered Research in Multiple Chronic Conditions. J. Clin. Med. 2021, 10, 2112. [CrossRef] [PubMed]

20. Skinner, H.G.; Coffey, R.; Jones, J.; Heslin, K.C.; Moy, E. The Effects of Multiple Chronic Conditions on Hospitalization Costs and Utilization for Ambulatory Care Sensitive Conditions in the United States: A Nationally Representative Cross-Sectional Study. BMC Health Serv. Res. 2016, 16, 77. [CrossRef]

21. Larsen, A.; Broberger, E.; Petersson, P. Complex Caring Needs without Simple Solutions: The Experience of Interprofessional Collaboration among Staff Caring for Older Persons with Multimorbidity at Home Care Settings. Scand. J. Caring Sci. 2017, 31, 342-350. [CrossRef]

22. Volkert, D.; Beck, A.M.; Cederholm, T.; Cereda, E.; Cruz-Jentoft, A.; Goisser, S.; de Groot, L.; Großhauser, F.; Kiesswetter, E.; Norman, K.; et al. Management of Malnutrition in Older Patients-Current Approaches, Evidence and Open Questions. J. Clin. Med. 2019, 8, 974. [CrossRef] [PubMed]

23. Yoshimura, Y.; Wakabayashi, H.; Bise, T.; Nagano, F.; Shimazu, S.; Shiraishi, A.; Yamaga, M.; Koga, H. Sarcopenia Is Associated with Worse Recovery of Physical Function and Dysphagia and a Lower Rate of Home Discharge in Japanese Hospitalized Adults Undergoing Convalescent Rehabilitation. Nutrition 2019, 61, 111-118. [CrossRef] [PubMed]

24. Short, N.; Shah, C. Muehrcke's Lines. Am. J. Med. 2010, 123, 991-992. [CrossRef]

25. Feliu, J.; Pinto, A.; Basterretxea, L.; López-San Vicente, B.; Paredero, I.; Llabrés, E.; Jiménez-Munárriz, B.; Antonio-Rebollo, M.; Losada, B.; Espinosa, E.; et al. Development and Validation of an Early Mortality Risk Score for Older Patients Treated with Chemotherapy for Cancer. J. Clin. Med. 2021, 10, 1615. [CrossRef] [PubMed] 
26. Watanabe, Y.; Tajiri, K.; Nagata, H.; Kojima, M. Determinants of in-Hospital Mortality in Elderly Patients Aged 80 Years or above with Acute Heart Failure: A Retrospective Cohort Study at a Single Rural Hospital. J. Clin. Med. 2021, 10, 1468. [CrossRef]

27. Akirov, A.; Masri-Iraqi, H.; Atamna, A.; Shimon, I. Low Albumin Levels Are Associated with Mortality Risk in Hospitalized Patients. Am. J. Med. 2017, 130, 1465.e11-1465.e19. [CrossRef]

28. Crimmins, E.M.; Shim, H.; Zhang, Y.S.; Kim, J.K. Differences between Men and Women in Mortality and the Health Dimensions of the Morbidity Process. Clin. Chem. 2019, 65, 135-145. [CrossRef]

29. Gordon, E.H.; Peel, N.M.; Samanta, M.; Theou, O.; Howlett, S.E.; Hubbard, R.E. Sex Differences in Frailty: A Systematic Review and Meta-Analysis. Exp. Gerontol. 2017, 89, 30-40. [CrossRef]

30. Sirri, L.; Fava, G.A.; Sonino, N. The Unifying Concept of Illness Behavior. Psychother. Psychosom. 2013, 82, 74-81. [CrossRef]

31. Ohta, R.; Sakamoto, N.; Maeno, T. Home Care Workers' Judgment of Acute Conditions in Home Care Patients: A Retrospective Cohort Study. Home Health Care Manag. Pract. 2020, 32, 3-9. [CrossRef]

32. Ohta, R.; Ryu, Y.; Kitayuguchi, J.; Gomi, T.; Katsube, T. Challenges and Solutions in the Continuity of Home Care for Rural Older People: A Thematic Analysis. Home Health Care Serv. Q. 2020, 39, 126-139. [CrossRef] [PubMed]

33. Ohta, R.; Ryu, Y.; Katsube, T.; Sano, C. Rural Homecare Nurses' Challenges in Providing Seamless Patient Care in Rural Japan. Int. J. Env. Res. Public Health 2020, 17, 9330. [CrossRef]

34. Ohta, R.; Ryu, Y.; Katsube, T. Care Managers in Rural Japan: Challenges to Interprofessional Collaboration. Home Health Care Serv. Q. 2019, 38, 270-285. [CrossRef]

35. Ohta, R.; Ryu, Y.; Katsube, T. Challenges for Japanese Rural Home Care Workers in Interprofessional Collaboration: A Qualitative Study. Home Health Care Serv. Q. 2018, 37, 313-324. [CrossRef]

36. Taylor, J.K.; Fleming, G.B.; Singanayagam, A.; Hill, A.T.; Chalmers, J.D. Risk Factors for Aspiration in Community-Acquired Pneumonia: Analysis of a Hospitalized UK Cohort. Am. J. Med. 2013, 126, 995-1001. [CrossRef]

37. Ponikowski, P.; Voors, A.A.; Anker, S.D.; Bueno, H.; Cleland, J.G.F.; Coats, A.J.S.; Falk, V.; González-Juanatey, J.R.; Harjola, V.P.; Jankowska, E.A.; et al. 2016 ESC Guidelines for the Diagnosis and Treatment of Acute and Chronic Heart Failure: The Task Force for the Diagnosis and Treatment of Acute and Chronic Heart Failure of the European Society of Cardiology (ESC) Developed with the Special Contribution of the Heart Failure Association (HFA) of the ESC. Eur. Heart J. 2016, 37, 2129-2200. [PubMed]

38. Stall, N.; Nowaczynski, M.; Sinha, S.K. Systematic Review of Outcomes from Home-Based Primary Care Programs for Homebound Older Adults. J. Am. Geriatr. Soc. 2014, 62, 2243-2251. [CrossRef]

39. Ohta, R.; Ueno, A.; Kitayuguchi, J.; Moriwaki, Y.; Otani, J.; Sano, C. Comprehensive Care through Family Medicine: Improving the Sustainability of Aging Societies. Geriatrics 2021, 6, 59. [CrossRef] [PubMed]

40. Singh, P.; Orzol, S.; Peikes, D.; Oh, E.G.; Dale, S. Participation in the Comprehensive Primary Care Plus Initiative. Ann. Fam. Med. 2020, 18, 309-317. [CrossRef]

41. Sung, N.J.; Choi, Y.J.; Lee, J.H. Primary Care Comprehensiveness Can Reduce Emergency Department Visits and Hospitalization in People with Hypertension in South Korea. Int. J. Environ. Res. Public Health 2018, 15, 272. [CrossRef] [PubMed]

42. Yani, M.; Si, S.; Budhi Irawan, M.T.; Casi Setiningsih, M.T.S.T. Application of Transfer Learning Using Convolutional Neural Network Method for Early Detection of Terry's Nail. J. Phys. Conf. Ser. 2019, 1201, 012052. [CrossRef] 